\title{
Quantification of $E$. coli DNA on a Flow-through Chemiluminescence Microarray Readout System after PCR Amplification
}

\author{
Simon C. DonhauSER, Reinhard NIESSNER, and Michael SEIDEL ${ }^{\dagger}$ \\ Institute of Hydrochemistry and Chair for Analytical Chemistry, Technische Universität München, \\ Marchioninistrasse 17, D-81377 München, Germany
}

\begin{abstract}
We report on a hybridization assay using DNA microarrays for the quantification of amplification products of the uidA gene of E. coli. Using the stopped-PCR strategy, the amplified target DNA was strongly dependent on the applied gene copies. The quantification was carried out by a flow-through chemiluminescence microarray readout system. The DNA microarrays were based on a poly(ethylene glycol)-modified glass substrate. The probes on the surface were 18 or 25 nucleotides long and the quantified PCR product was 60 nucleotides. The amplification was stopped after 25 cycles; at this point amplification was in the middle of the logarithmical phase, and the spread between different DNA starting concentrations reached the maximum. A conjugate of streptavidin and horseradish peroxidase (HRP) bound to the biotinylated strands on the microarray surface and catalyzed the reaction of luminol and hydrogen peroxide. The generated light emission was recorded by a sensitive charge-coupled device (CCD) camera. The detection limit for the gene uidA ( $\beta$-galactosidase) of $E$. coli was $1.1 \times 10^{5}$ copies $/ \mathrm{mL}$. This system allowed for a sensitive detection and quantification of $E$. coli in a concentration range from $10^{6}$ to $10^{9}$ copies $/ \mathrm{mL}$.
\end{abstract}

(Received October 10, 2008; Accepted December 22, 2008; Published May 10, 2009)

\section{Introduction}

Water monitoring and quality control are important for public health. Traditional microbiological methods for drinking-water analysis are labor intensive, and days can pass until valid results are achieved. Therefore, waterworks and industry are highly interested in fast and sensitive test systems for the analysis of human pathogens. In addition to pesticides, pharmaceuticals, and toxins, pathogenic microorganisms are the most dangerous water contaminants, which have to be detected and identified immediately in order to prevent an outbreak of water-borne diseases. ${ }^{1}$ Pathogenic bacteria can be considered as possible biological weapons. Therefore, water control is of great interest for military defense and homeland security. ${ }^{2}$ Enabling quick and early interventions after a contamination event, fast, sensitive, and especially multianalyte screening methods that can be integrated in automated systems are needed.

Until now, mainly microbiological methods have been applied for the routine detection of bacteria, which include selective preenrichment steps through cultivation, and a number of serological and biochemical tests for identification. ${ }^{3,4}$ These tests usually provide for reliable and robust results (no falsepositives), and only viable cells are detected. However, they are very time-consuming (e.g. $18 \mathrm{~h}$ for E. coli; 10 days for Legionella) and labor-intensive. The number of samples for routine detection is limited. These methods are not well suited for the detection of pathogens in drinking water. ${ }^{5}$

For microorganism detection, DNA microarrays can also be used for the quantification in food or water samples. ${ }^{6,7}$ For these analytical purposes, fluorescence, electrochemical, chemiluminescence (CL) and label-free microarray read-out systems have been developed. ${ }^{8-14}$ CL microarrays use the effect of light emission caused by a chemical reaction with the assistance of an enzyme label. In contrast to fluorescence, there is no background signal, neither from the light source nor from light scattering of the matrix. Therefore, CL is the most sensitive readout principle for microarrays. ${ }^{15}$ The signal intensity per enzyme label can even be increased while one uses optimized CL substrates. ${ }^{16}$

Even this sensitive detection system relies on a preceeding amplification step. Best suited for this is the PCR amplification of nucleic acids. This amplification method is a powerful way to increase the sensitivity of a DNA microarray. Unfortunately, it has one major drawback concerning working principle. PCR amplifies the target DNA until the limiting factor in the reaction mix is used-up. This leads to a sigmoidal amplification curve (Fig. 1a). At the end, all samples are aligned to the same end concentration, independent of the used starting concentration (unpublished data).

At our institute we have developed the stopped-PCR method (Fig. 1b). It allows the sensitive quantification of target DNA after PCR amplification using a highly sensitive chemiluminescence DNA microarray (Fig. 1c). The amplification is stopped at that point of the reaction when the spread between different starting amounts of target DNA reaches a maximum. In combination with the sensitive microarray this enables a very sensitive quantification assay.

$\dagger$ To whom correspondence should be addressed.

E-mail: michael.seidel@ch.tum.de 
a)

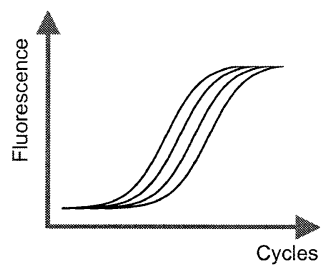

b)

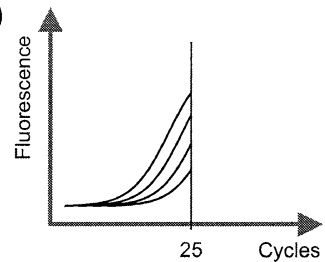

c)

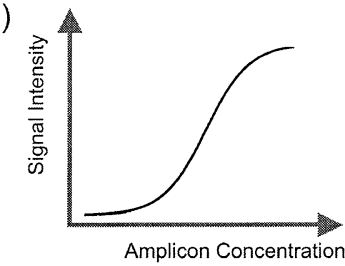

Fig. 1 Scheme of real-time PCR (a), stopped-PCR (b), and the quantification of amplicons after stopped-PCR on a DNA microarray (c).

\section{Experimental}

\section{Chemicals, reagents, and materials}

Standard chemicals were purchased from Sigma-Aldrich (Taufkirchen, Germany) or VWR (Darmstadt, Germany). 3Glycidyloxypropyltrimethoxysilane (GOPTS) was supplied by Fluka/Sigma-Aldrich (Taufkirchen, Germany). Dimethylaminopyridine (DMAP), di( $N$-succinimidyl)-carbonate (DSC), anhydrous dimethylformamide (DMF), triethylamine (TEA), and casein were obtained from Sigma-Aldrich. Streptavidin labeled with horseradish peroxidase was purchased from Axxora (Lörrach, Germany). The chemiluminescence substrate SuperSignal ELISA Femto Maximum Sensitivity Kit was purchased from Pierce (Rockford, IL). Hellmanex II was obtained from Hellma (Müllheim, Germany). Phosphate buffered saline (PBS) containing $145 \mathrm{mM} \mathrm{NaCl}, 10 \mathrm{mM}$ $\mathrm{KH}_{2} \mathrm{PO}_{4}$, and $70 \mathrm{mM} \mathrm{K} \mathrm{HPO}_{4}$, adjusted to $\mathrm{pH} 7.6$ and was used as a buffer solution. The running buffer consisted of $0.5 \%$ casein (w/v) in PBS ( $\mathrm{pH} 7.6)$. The regeneration buffer contained $100 \mathrm{mM}$ glycine, $100 \mathrm{mM} \mathrm{NaCl}$ and $0.1 \%$ sodium dodecyl sulfate (SDS) adjusted to $\mathrm{pH} 3$. For spotting, PCR-grade water from Roche Diagnostics (Mannheim, Germany) was used. The carbonate buffer contained $15 \mathrm{mM} \mathrm{Na} \mathrm{CO}_{3}, 35 \mathrm{mM} \mathrm{NaHCO}$ and $3 \mathrm{mM} \mathrm{NaN}_{3}$, and was adjusted to $\mathrm{pH}$ 9.6. Betaine was dissolved in a $1 \times \mathrm{SSC}$ buffer $(150 \mathrm{mM} \mathrm{NaCl}, 15 \mathrm{mM}$ sodium citrate). All buffers and solutions were prepared freshly prior to each experiment. Menzel glass slides $(26 \mathrm{~mm} \times 76 \mathrm{~mm} \times$ $1 \mathrm{~mm}$ ) were purchased from Roth (Karlsruhe, Germany). Activation of the glass slides and cleaning steps were performed in plastic reservoirs from Roth. Microtiter plates (384-well), used as substrates for the spotting solutions, were obtained from VWR (BD FalconTM, reference 353265, natural polypropylene, flat bottom, nonsterile, Lot 06291155, low binding). Diamino PEG 2000 (DAPEG, $2000 \mathrm{~g} / \mathrm{mol}$ ) was kindly provided as a gift by Huntsman Holland (Rozenburg, The Netherlands).

\section{DNA probes, primers and plasmids}

Primers and probes were designed using Primer 3 on the universal probe library homepage (http://www.universalprobelibrary.com) and the arb package. ${ }^{17}$ All oligonucleotides were synthesized by FRIZbiochem (Neuried, Germany), and have been HPLC purified. The following sequences have been used: $E$. coli uidA probe amino-C6-5'-GGTTCGTTGGCAATACTC-3', uidA FRET hydrolysis probe FAM-5'-CATCACCA-3'-anthrachinon, uidA forward primer 5'-CGGTTCGTTGGCAATACTC-3' ${ }^{\prime}$, uidA reverse primer biotin-5'-CTGATAGCGCGTGACAAAAA-3', 16S rDNA probe for Raoultella planticola amino-C6-5'CTGGCAAGCTTGAGTCTTGTAGAGG-3' and its antistrand 5'-GACCGTTCGAACTCAGAACATCTCC-3'-biotin. The following stock solutions were prepared: $10 \mathrm{mg} / \mathrm{mL}$ for the probes, $100 \mu \mathrm{M}$ for the hydrolysis probe and $200 \mu \mathrm{M}$ for the primers.

The vectors are provided by a collaborator (see acknowledgements). The uidA sequence amplified via PCR was cloned into the vector pGEM-T. Then, the vector was linearized using an Apa I digestion. The concentration was determined using a Nanodrop spectrophotometer from Thermo Fisher Scientific (Wilmington, DE).

\section{Instrumentation}

The setup consists of an automated pump panel connected to a manually operated rotary valve. After pumping the solutions through the flow cell, they either are delivered immediately into the waste, or in the case of the sample a 4-way valve can collect the sample and recycle it. If the sample is double-stranded, as a PCR product usually is, it has to be denatured for $10 \mathrm{~min}$ at $95^{\circ} \mathrm{C}$ in a water bath, followed by a cooling step in an ice bucket at $0^{\circ} \mathrm{C}$ for $1 \mathrm{~min}$, and can then be incubated in the flow cell to allow the binding event to take place (Fig. 2). Single-stranded oligonucleotides are only flown through the flow cell one time, and are then discarded immediately.

\section{Surface chemistry for DNA microarrays}

Surface chemistry was developed at our institute and was adapted for oligonucleotide microarrays. ${ }^{18,19}$ In order to remove glass dust and organic contaminants, glass slides were shaken overnight in a solution of $2 \%$ Hellmanex in water. The slides were washed with Millipore water and treated with a freshly prepared $1: 1$ mixture of $37 \% \mathrm{HCl}$ and methanol for $1 \mathrm{~h}$ by shaking. After the slides were washed with Millipore water, they were shaken for $1 \mathrm{~h}$ in $99-100 \% \mathrm{H}_{2} \mathrm{SO}_{4}$. The activated slides were cleaned with Millipore water and dried in a $\mathrm{N}_{2}$ stream and in a drying cabinet at $70^{\circ} \mathrm{C}$ for 15 min consecutively.

After activation, the slides were directly silanized with GOPTS by a sandwich technique for $1 \mathrm{~h}$ at room temperature in glass chambers. For creating the sandwiches, $600 \mu \mathrm{L}$ of GOPTS were given to an activated slide that was covered with a second glass slide. The slides were separated in pure ethanol and were cleaned successively in ethanol, methanol, and ethanol by sonication for $15 \mathrm{~min}$. Afterwards, they were dried under a $\mathrm{N}_{2}$ stream and in a drying cabinet at $70^{\circ} \mathrm{C}$ for $15 \mathrm{~min}$. The silanized glass slides were stored in vacuo at room temperature until further modification.

In order to minimize background signals, a poly(ethylene glycol)diamine (DAPEG) film was built up on the silanized slides. PEG terminated surfaces are known to prevent the nonspecific binding of proteins (e.g. unspecific HRP adsorption) ${ }^{20}$ Furthermore, the PEG molecules (2000 Da) act as long crosslinkers between the solid substrate and the immobilized DNA, which contributes to a good DNA exposure to the antistrand. PEG layers were prepared by delivering approximately $1 \mathrm{~mL}$ of liquid DAPEG on a silanized glass slide and covering the coated slide with another silanized slide. The sandwiches were baked overnight in an oven at $100^{\circ} \mathrm{C}$. The slides were separated in Millipore water and were sonicated two times in Millipore water for $15 \mathrm{~min}$. Finally, the slides were dried under a $\mathrm{N}_{2}$ stream and in a drying cabinet for $15 \mathrm{~min}$ at $70^{\circ} \mathrm{C}$. The DAPEG-coated slides were stored in vacuo at room temperature. 


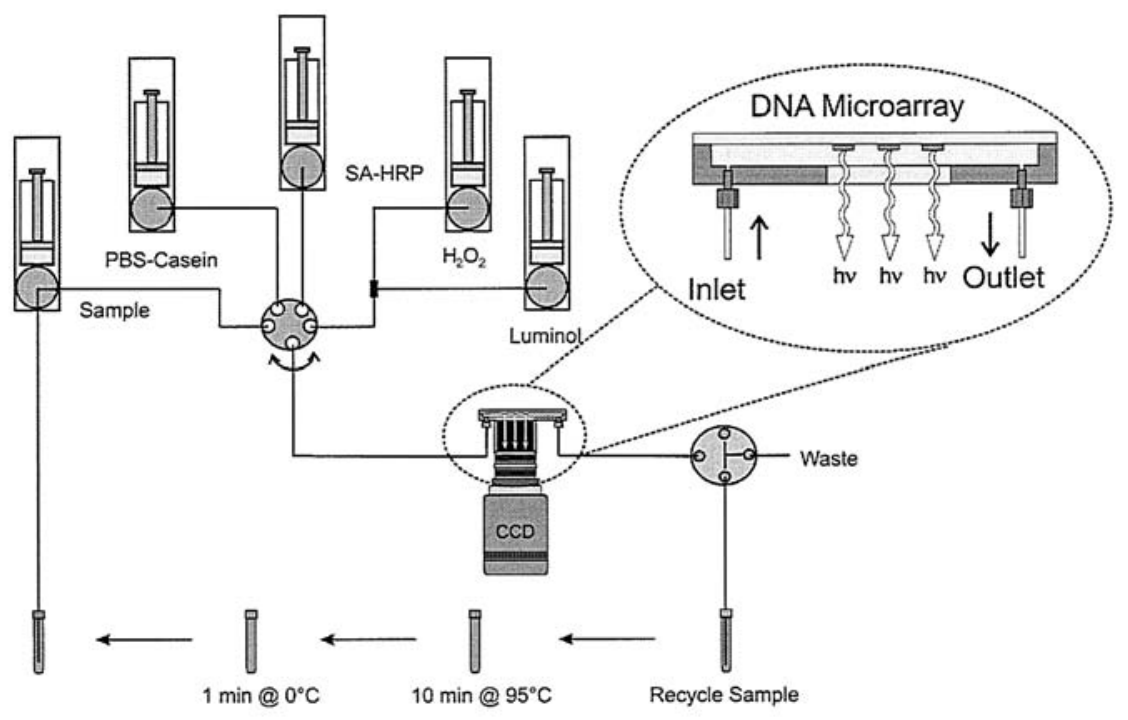

Fig. 2 Flow scheme for the chemiluminescence microarray readout system.

For covalent immobilization of DNA via free amines, the slides were further modified by a reaction with DSC to obtain a $\mathrm{N}$-hydroxysuccinimide (NHS) activated surface. For NHS activation, the sandwich technique was applied again. An amount of $600 \mu \mathrm{L}$ of a solution of $40 \mathrm{mg}$ of DSC, $2 \mathrm{mg}$ of DMAP, and $63 \mu \mathrm{L}$ of triethylamine in water-free DMF were dispensed on one DAPEG-coated slide, which was then covered by a second one. The sandwiches were incubated for $4 \mathrm{~h}$ at room temperature in glass chambers. The sandwiches were separated in a chamber containing methanol and were cleaned twice with methanol by sonication for $10 \mathrm{~min}$ each time. Finally, the activated slides were dried under $\mathrm{N}_{2}$ and stored in vacuo until printing.

\section{Microcontact printing of DNA}

For all microarray hybridization assays, capture probes were covalently immobilized onto NHS-activated DAPEG-functionalized glass substrates by means of a BioOdyssey Calligrapher contact printer from Bio-Rad (München, Germany). This contact printer provided temperature and humidity control.

For the measurement of Escherichia coli, the uidA probe was immobilized; for Raoultella planticola the 16S rDNA probe was used. Capture probes were prepared in PCR-grade water and were deposited onto the activated DAPEG surfaces using a TeleChem Stealth SNS9 microspotting pin, which transferred a volume of approximately $1 \mathrm{~nL}$ of sample per spot. The humidity of the chamber was set to $35 \%$ in order to prevent surface inactivation by humidity. The air temperature inside the chamber was $20^{\circ} \mathrm{C}$. Aliquots $(30 \mu \mathrm{L})$ of the DNA solutions in PCR-grade water were transferred to the wells of a 384-well MTP, placed in the microcontact printer.

For measuring dose-response curves, a $3 \times 6$ array grid was defined by means of the software "Calligrapher" (Bio-Rad, München, Germany). Each of the three printed samples were deposited in replicates of six spots with a spacing of $1100 \mu \mathrm{m}$. The grid spacing between the different rows was $1500 \mu \mathrm{m}$. In the first row, amino-biotin was printed in a final concentration of $1 \mathrm{mg} / \mathrm{mL}$ in PCR-grade water that was used as a positive control for streptavidin-HRP. In the second row, PCR-grade water without DNA was printed, which served as a negative control. Finally, in row three the capture probe was printed.

After printing, the microarrays were stored in Petri dishes in a drying cabinet at $60^{\circ} \mathrm{C}$ overnight. In order to saturate free binding sites of the microarray surface and to reduce any background effects, the printed slides were blocked by rigid mixing for $1 \mathrm{~min}$ in $50-\mathrm{mL}$ reagent tubes containing a blocking solution (tris(hydroxymethyl)aminomethane hydrochloride (Tris- $\mathrm{HCl}$ ) buffer, $3 \mathrm{M}, \mathrm{pH} 8.5$ ), followed by $1 \mathrm{~min}$ of rinsing with MilliQ water and 1 min of shaking in methanol. Then, the slides were dried under a $\mathrm{N}_{2}$ stream. Slides could be stored for several weeks at $-20^{\circ} \mathrm{C}$ until use.

\section{DNA isolation, quantification and DNA standards}

DNA isolation has been achieved by using a blood \& tissue kit from Qiagen (Hilden, Germany) according to the manufacturer's recommendations. For quantification, a Nanodrop from Thermo Fisher Scientific (Wilmington, DE) has been used. DNA standards were a gift of TZW (Karlsruhe, Germany).

\section{Stopped-PCR amplification}

First, $1 \mu \mathrm{L}$ of sample DNA was mixed with hydrolysis probe PCR reagents from Roche Diagnostics (Mannheim, Germany) according to the manufacturer's recommendations. The final concentration of the probe was $100 \mathrm{nM}$; the primers were used with $200 \mathrm{nM}$ each. All PCR reactions were carried out on a Light Cycler 480 system from Roche Diagnostics (Mannheim, Germany) with the following protocol: The first step was 10min denaturation of the DNA and activation of the polymerase at $95^{\circ} \mathrm{C}$. The cycling was done with a three-step protocol: $10 \mathrm{~s}$ at $95^{\circ} \mathrm{C}, 25 \mathrm{~s}$ at $60^{\circ} \mathrm{C}$ and $1 \mathrm{~s}$ at $72^{\circ} \mathrm{C}$. The cycling was repeated and then stopped after 25 cycles.

\section{Flow-through chemiluminescence readout system and assay conduction}

The chemiluminescence microarray readout system with an automated reagent supply is a further development of the setup described earlier. ${ }^{21}$ Setup modifications include the use of an adhesive foil to produce the flow cell. A glass slide with the DNA microarray is glued with the printed array surface side to the planar polycarbonate carrier with the laser-cut double-sided adhesive foil ARcare 90106. The foil is a clear, thin and flexible plastic film coated on both sides with an acrylic hybrid medicalgrade pressure-sensitive adhesive, which acts as an accurately defined spacer for both slides. The total height of $142 \mu \mathrm{m}$ defines the volume of the flow channel, and assures a laminar flow and an equal distribution of fluids around the active field of 
the microarray. The microfluidic channel was laser cut into the adhesive foil before gluing it to the carrier. The liquid volume of the channel is $62 \mu \mathrm{L}$. The transparent polycarbonate slide possesses an inlet and an outlet connection. After the microarray was placed in the microarray reader the connections were sealed with a cap by pressure.

The pumping parameters of each pump including volumes, speed, intervals, and interruptions can be adjusted with the software Immunomat V7 from Atto-tec GmbH (Siegen, Germany). Since the positions of the selection valve have to be set manually, so far the whole assay protocol can only be executed semiautomatically. For each assay, the chemiluminescence reaction was generated with a 1:1 mixture of "Supersignal ELISA Femto Luminol Enhancer Solution" and "Supersignal ELISA Femto Stable Peroxide Solution". After insertion of the DNA microarray in the flow-through chemiluminescence readout system, all steps of the hybridization assay were carried out there.

The general assay protocol for the measurement of DNA is summarized as follows: after a rinsing step with running buffer (PBS with $0.5 \%$ casein, $2 \mathrm{~mL}, 20 \mu \mathrm{L} / \mathrm{s}$ ), $0.5 \mathrm{~mL}$ of a DNA solution in PBS was denatured for $10 \mathrm{~min}$ at $95^{\circ} \mathrm{C}$, then cooled on ice for $1 \mathrm{~min}$. After that it was pumped over the chip in steps of $20 \mu \mathrm{L}$, followed by an incubation time of $3 \mathrm{~s}$. The denaturation and incubation cycle was repeated 20 times. In the case of using single-stranded synthesized oligonucleotides, the sample was not denatured prior to incubation, and the incubation was not repeated 20 times. Then, $2.0 \mathrm{~mL}$ of a solution of HRP-labeled streptavidin in a running buffer at a final concentration of 0.1 $\mu \mathrm{g} / \mathrm{mL}$ was passed over the chip. The flow cell was washed with running buffer $(4 \mathrm{~mL}, 20 \mu \mathrm{L} / \mathrm{s})$, and consecutively each 600 $\mu \mathrm{L}$ of the two chemiluminescence substrates were simultaneously pumped into the flow cell at a flow rate of $20 \mu \mathrm{L} / \mathrm{s}$. Finally, the chemiluminescence signals were integrated for $90 \mathrm{~s}$. The overall assay time was $7 \mathrm{~h}$ if a double-stranded PCR product had been used, and $15 \mathrm{~min}$ if single-stranded synthesized oligonucleotides had been used. In the case of regeneration experiments, the flow cell was regenerated using regeneration buffer $(5 \mathrm{~mL}, 20 \mu \mathrm{L} / \mathrm{s})$. After the measurements, the whole system was thoroughly cleaned with water and a solution of $1 \%(\mathrm{v} / \mathrm{v})$ Hellmanex in water. For determining the dose-response curve (Fig. 8) the following concentrations were measured: blank (PBS), $1 \times 10^{6}$, $1 \times 10^{7}, 1 \times 10^{8}, 1 \times 10^{9}$ copies $/ \mathrm{mL}$.

\section{Data processing}

The background originating from the CCD dark signal was recorded before a measurement, and was substracted from each image prior to evaluation. The signal intensities of each spot were integrated over seven pixels, and the mean value as well as the standard deviation of the integrals were determined for six spot replicates per DNA probe. These calculations were also applied for pixels located on the chip background. The mean background integrals were then substracted from the mean spot integrals. Dose-response curves were obtained by plotting these background-corrected chemiluminescence signals in a logarithmic scale against different concentrations of DNA. The standard errors of the values are indicated in the diagrams as error bars. The limit of detection (LOD) was determined to be the concentration where $S / N=3$ was reached, whereas the $S$ and $N$ values also represented integrated CL signals.

\section{Results and Discussion}

Detection of bacterial DNA on a DNA microarray platform For the quantification of DNA, a chemiluminescence

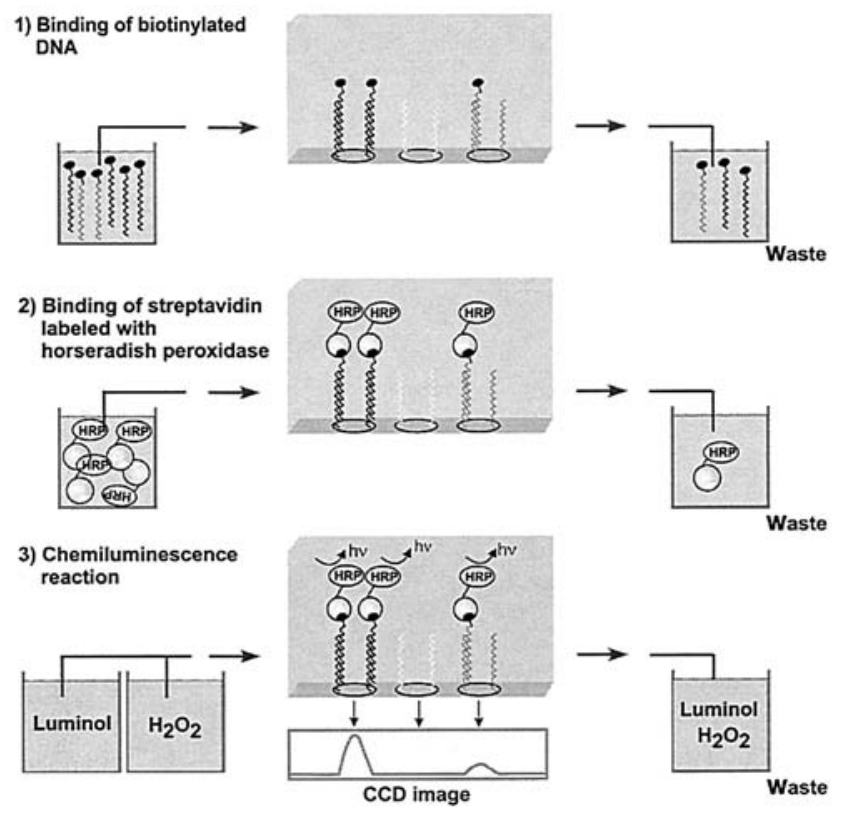

Fig. 3 Scheme of the assay principle illustrated for the detection of three different genes on the DNA microarray surface.

hybridization assay was performed on a DNA microarray surface. The target DNA has to be labelled with biotin. This either happens by the use of a biotinylated reverse primer during PCR amplification or during synthesis of the oligonucleotides. The target DNA was captured by specific DNA probes, which had been covalently immobilized on PEG modified glass substrates. The interaction of the target and the probe DNA is responsible for the specificity of the assay. All assay steps, including the consecutive addition of single-stranded biotinylated DNA (Fig. 3, step 1), HRP labelled streptavidin (Fig. 3, step 2) and chemiluminescence substrates (Fig. 3, step 3) were conducted with the flow-through chemiluminescence readout system. The surface chemistry was optimized in such a way as to reduce unspecific binding of HRP and target DNA. Also, the conditions for the coupling reaction of the DNA probes were optimized as follows.

Optimized microarray production on PEG activated glass slides

For optimization of the surface chemistry, 12 different spotting buffers were evaluated (Fig. 4). They are rated according to their signal intensity and stability in regeneration experiments. Betaine and trehalose were tested because of their hygroscopic characteristics. Their addition to the spotting solution should increase the reaction time for the coupling reaction before it is stopped by drying-up. Borate and carbonate buffers (CB) were tested because of their alkalinity. The coupling reaction is favored under alkaline conditions. Tween, being a detergent, was tested to reduce the surface tension of the spotting droplet, and to increase the spot size. Overall PCR-grade water had the best spot size, signal intensity and signal stability in combination with the DAPEG-NHS surface chemistry during the regeneration experiments (Figs. 4, 5). The maximum $S / N$ was 618:1. The signal of the DNA probes spotted in water was decreasing between the first use of the microarray and the second regeneration. However after the second regeneration, all unbound DNA probes were washed away, and only the covalently bound probes remained, resulting in a constant signal for up to 17 regenerations (Fig. 5). 


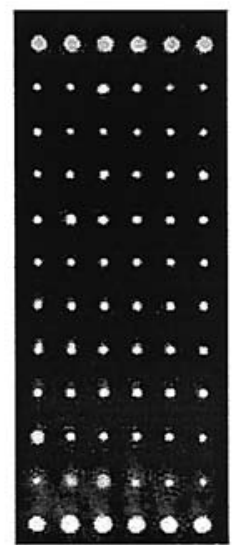

\begin{tabular}{|l|l|}
\hline $0.001 \%$ Tween-20 in CB & Detergent \\
\hline $0.01 \%$ Tween-20 in CB & Detergent \\
\hline $10 \%$ Trehalose in CB & No evaporation \\
\hline $5 \%$ Trehalose in CB & No evaporation \\
\hline $0.009 \mathrm{M}$ Borate $(\mathrm{pH} 9)$ & Alkaline \\
\hline $0.09 \mathrm{M}$ Borate $(\mathrm{pH} 9)$ & Alkaline \\
\hline $0.1 \mathrm{M}$ Betaine + SSC & Hygroscopic \\
\hline $1 \mathrm{M}$ Betaine + SSC & Hygroscopic \\
\hline $1.5 \mathrm{M}$ Betaine + SSC & Hygroscopic \\
\hline $2 \mathrm{M}$ Betaine + SSC & Hygroscopic \\
\hline Carbonate buffer $(\mathrm{pH} 9.5)$ & Alkaline \\
\hline Water & Neutral \\
\hline
\end{tabular}

Fig. 4 Comparison of 12 spotting buffers for DNA microarray production on a DAPEG-NHS surface.

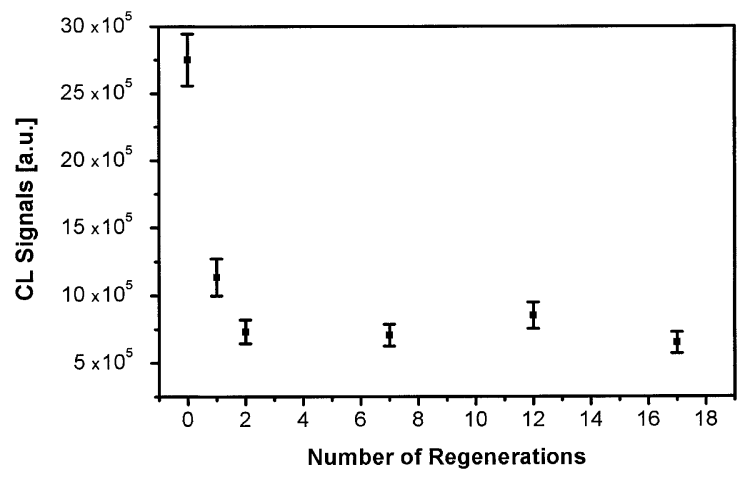

Fig. 5 Signal stability of PCR-grade water spotted DAPEG-NHS surface chemistry from 2 to 17 regenerations. The 16S rDNA probe for $R$. planticola with its oligonucleotide antistrand has been used.

Calibration of the DNA microarray with synthesized oligos

Using a single-stranded 25mer antisense strand to an immobilized 16S rDNA sequence for Raoultella planticola, as an analyte, reveals the high sensitivity of the developed chemiluminescence DNA microarray surface chemistry. This assay is able to detect 40 copies $/ \mathrm{mL}$ within $15 \mathrm{~min}$, and has a dynamic range of between $10^{6}$ and $10^{16}$ copies $/ \mathrm{mL}$ (Fig. 6). The maximum $S / N$ was 225:1. Remarkable is the large dynamic range of 10 decades and the very short assay time. Usually, hybridization assays have an incubation time of several hours. This sensitivity and speed allow for the setup of the next section. It is possible to even meassure very low DNA concentrations immediately after the amplification curve in the realtime PCR has reached the crossing point $(\mathrm{CP})$. The microarray is at least as sensitive as the fluorescence detection system of a realtime PCR machine, if not even better. The sensitivity is not an issue with this system. However, for drinking-water analysis an exact quantification is required, and certain thresholds have to be monitored. This leads to the development of a quantification method, including PCR amplification.

\section{Quantification principle}

Endpoint-PCR makes use of the whole amplification potential of the PCR reaction. The target DNA sequence is amplified until one limiting factor of the reaction mix is used-up. This leads to a sigmoidal amplification curve (Fig. 7). At the end, all samples are aligned to roughly the same end concentration, independent of the used starting concentration (unpublished

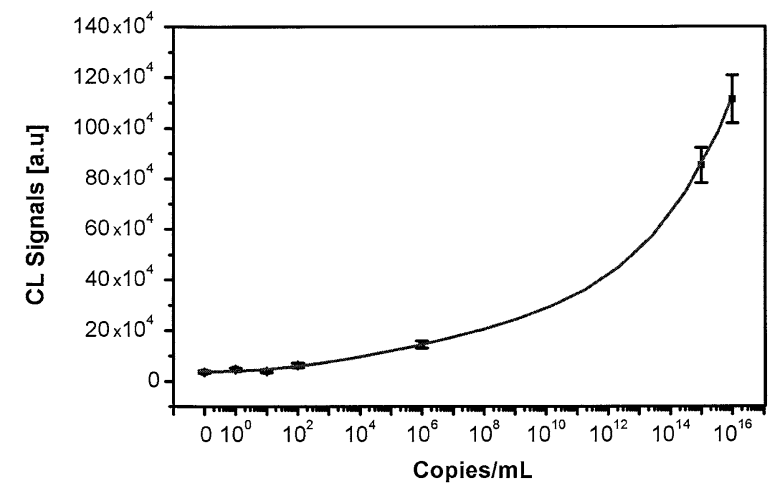

Fig. 6 Dose-response curve $(n=6)$ for $16 \mathrm{~S}$ rDNA of $R$. planticola.

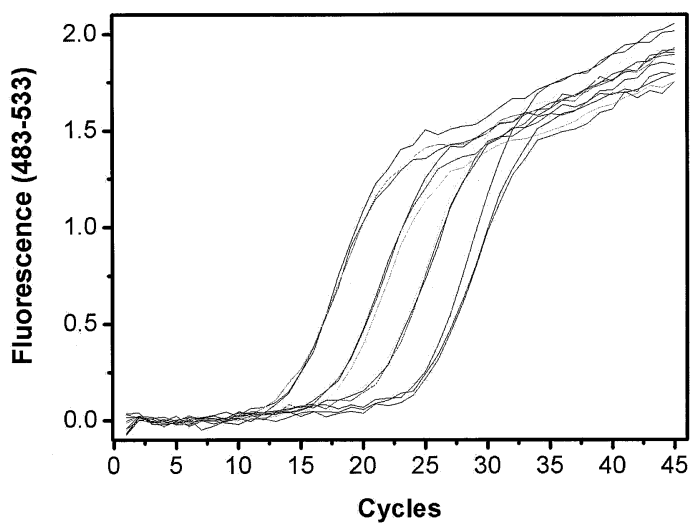

Fig. 7 Realtime PCR amplification monitored by fluorescence in a hydrolysis probe assay. Amplification curves for $10^{6}$ to $10^{9}$ copies $/ \mathrm{mL}$ are shown.

data). In our stopped-PCR assay, PCR amplification is stopped at cycle number 25. Stopping the amplification in the logarithmic phase generates a maximum spread between different amounts of starting material (Fig. 7). This fact allows for quantification with a DNA microarray after PCR amplification. Figure 7 shows the amplification curves for $10^{6}$ to $10^{9}$ copies $/ \mathrm{mL}$ of the uidA DNA.

\section{Quantification}

A dose-response curve for uidA has been recorded. Starting with different copy numbers of the uidA DNA sequence, a part of the gene uidA was amplified using the stopped-PCR method. Then, the PCR product was denatured and flown over the microarray. After PCR amplification, the limit of detection was $1.1 \times 10^{5}$ copies $/ \mathrm{mL}$. The dynamic range was between $10^{6}$ and $10^{9}$ copies/mL (Fig. 8). The maximum $S / N$ was $354: 1$. Depending on the performance of the preenrichment steps and the legal limits that have to be met, the PCR amplification can be stopped at a later cycle to increase the sensitivity, or can be stopped earlier, if needed.

\section{Conclusions}

We have developed a method, that combines the strong and fast amplification of neucleic acids by PCR and the sensitive detection of neucleic acids by a DNA microarray in a way that allows not only the sensitive detection of bacterial DNA, but also its quantification. The method is adjustable to meet the 


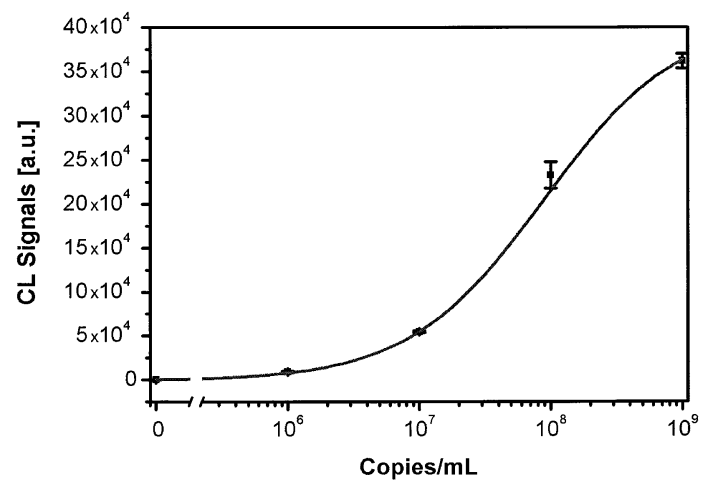

Fig. 8 Dose-response curve $(n=5, m=6)$ for uidA of $E$. coli.

requirements of the legal limits.

The chemiluminescence DNA microarray is very fast and sensitive if used with single-stranded DNA as the analyte. The assay time is $15 \mathrm{~min}$ and the limit of detection is 40 copies $/ \mathrm{mL}$. These facts implicate that the two strands synthesized by PCR amplification should be separated prior to the hybridization assay on the DNA microarray. Since the reverse primer is already labelled with biotin, a separation using streptavidinlabelled microbeads preceeding the hybridization assay could be a fast way to separate the strands. In addition, the forward primer would have to be labeled with a different label for binding a HRP-antibody conjugate to generate the chemiluminescence signal. The antibody would be against the second label. These variations would reduce the assay time for the hybridization assay with the double-stranded PCR product from $7 \mathrm{~h}$ to below $30 \mathrm{~min}$, and would dramatically increase the sensitivity to 40 copies/mL.

However, legal regulations in Germany require the detection of a single cell per $100 \mathrm{~mL}$ of drinking water. In order to meet this demand, and to achieve levels of bacteria detectable by the presented technique, sample preenrichment and preconcentration steps will be necessary prior to the analysis. Consequently, for the flow-through chemiluminescence microarray readout system to be used in water monitoring, the system will have to be integrated in an inline setup with preenrichment modules, such as microfiltration and immunomagnetic separation. In this way, the detection times would increase, but the common microbiological enrichment methods still take much longer and are more laborious. Furthermore, for this application, an extension of the detectable gene spectrum would be important. The active area of the chip still offers considerable free space for this. Hence, the integration of a variety of additional DNA probes is possible on the presented platform. Multiplexing experiments are the next step towards exploiting the power of a microarray.

Finally, the whole assay will be integrated into the Munich Chip Reader 3.22 This fully automated chip reader is already under evaluation for fast routine measurements of antibiotics in milk.

\section{Acknowledgements}

This research project was supported by the Federal Ministry of Education and Research (BMBF AquaSens, 02WU0865). We gratefully thank Xaver Karsunke and York Karsunke for developing the spot evaluation program. We thank the Huntsman Corporation for kindly providing us with a free sample of PEG and Mrs. Stoll from TZW Karlsruhe for preparing DNA standards for realtime PCR experiments.

\section{References}

1. S. D. Richardson, Anal. Chem., 2007, 79, 4295.

2. D. Ivnitski, I. Abdel-Hamid, P. Atanasov, and E. Wilkins, Biosens. Bioelectron., 1999, 14, 599.

3. N. S. Hobson, I. Tothill, and A. P. F. Turner, Biosens. Bioelectron., 1996, 11, 455.

4. C. W. Kaspar and C. Tartera, Methods Microbiol., 1990, 22, 497.

5. J. Hasan, S. States, and R. J. Deininger, Contemp. Water Res. Ed., 2004, 129, 27.

6. B. Spielbauer and F. Stahl, Mol. Nutr. Food Res., 2005, 49, 908.

7. D. Y. Lee, K. Shannon, and L. A. Beaudette, J. Microbiol. Meth., 2006, 65, 453.

8. C. R. Rowe, L. M. Tender, M. J. Feldstein, J. P. Golden, S. B. Scruggs, B. D. MacCraith, J. J. Cras, and F. S. Ligler, Anal. Chem., 1999, 71, 3846.

9. G. L. Duveneck, A. P. Abel, M. A. Bopp, G. M. Kresbach, and M. Ehrat, Anal. Chim. Acta, 2002, 469, 49.

10. J. Tschmelak, G. Proll, J. Riedt, J. Kaiser, P. Kraemmer, L. Barzaga, J. S. Wilkinson, P. Hua, J. P. Hole, R. Nudd, M. Jackson, R. Abuknesha, D. Barcelo, S. Rodriguez-Mozaz, M. J. Lopez de Alda, F. Sacher, J. Stien, J. Slobodnik, P. Oswald, H. Kozmenko, E. Korenkova, L. Tothova, Z. Krascsenits, and G. Gauglitz, Biosens. Bioelectron., 2005, 20, 1499.

11. B. Elsholz, R. Wörl, L. Blohm, J. Albers, H. Feucht, T. Grunewald, B. Jürgen, T. Schweder, and R. Hintsche, Anal. Chem., 2006, 78, 4794.

12. M. G. Weller, A. J. Schuetz, M. Winklmair, and R. Niessner, Anal. Chim. Acta, 1999, 393, 29.

13. K. A. Heyries, M. L. Loughran, D. Hofmann, A. Homsy, L. J. Blum, and C. A. Marquette, Biosens. Bioelectron., 2008, 23, 1812.

14. M. Bally, M. Halter, J. Vörös, and H. M. Grandin, Surf. Interface Anal., 2006, 38, 1442.

15. A. Roda, M. Guardigli, E. Michelini, M. Mirasoli, and P. Pasini, Anal. Chem., 2003, 75, 462.

16. R. S. Chouhan, K. Vivek Babu, M. A. Kumar, N. S. Neeta, M. S. Thakur, B. E. Amitha, A. Pasha, N. G. K. Karanth, and N. G. Karanth, Biosens. Bioelectron., 2006, 21, 1264.

17. W. Ludwig, O. Strunk, R. Westram, L. Richter, H. Meier, Yadhukumar, A. Buchner, T. Lai, S. Steppi, G. Jobb, W. Förster, I. Brettske, S. Gerber, A. W. Ginhart, O. Gross, S. Grumann, S. Hermann, R. Jost, A. König, T. Liss, R. Lüssmann, M. May, B. Nonhoff, B. Reichel, R. Strehlow, A. Stamatakis, N. Stuckmann, A. Vilbig, M. Lenke, T. Ludwig, A. Bode, and K. H. Schleifer, Nucleic Acids Res., 2004, 32, 1363.

18. A. Wolter, R. Niessner, and M. Seidel, Anal. Chem., 2007, 79, 4529 .

19. A. Wolter, R. Niessner, and M. Seidel, Anal. Chem., 2008, 80, 5854.

20. E. Ostuni, R. G. Chapman, M. N. Liang, G. Meluleni, G. Pier, D. E. Ingber, and G. M. Whitesides, Langmuir, 2001, 17, 6336.

21. B. G. Knecht, A. Strasser, R. Dietrich, E. Märtlbauer, R. Niessner, and M. G. Weller, Anal. Chem., 2004, 76, 646.

22. K. Kloth, R. Niessner, and M. Seidel, Biosens. Bioelectron., 2009, 24, 2106. 